\title{
DYNAMICS OF SUSPENDED SEDIMENT FLUX ON THE RIVERS BANDON AND OWENABUE, IRELAND
}

\author{
S.T. HARRINGTON ${ }^{1} \&$ J.R. HARRINGTON ${ }^{2}$ \\ ${ }^{1}$ Department of Civil, Structural \& Environmental Engineering, Cork Institute of Technology, Ireland. \\ ${ }^{2}$ School of Building and Civil Engineering, Cork Institute of Technology, Ireland.
}

\begin{abstract}
Monitoring, analysis and modelling of suspended sediment transport in riverine systems has received much attention in recent decades. Quantitive analysis techniques have been applied to allow river basin managers to assess suspended sediment transport and its importance in transporting a range of pollutants including excess metals and nutrients, which negatively impact on aquatic systems. In this paper, an analysis of the suspended sediment flux (SSF) dynamics is presented for the small and medium sized catchments of the River Owenabue and the River Bandon, respectively. The results contribute to the filling of a research gap in an Irish context where SSF analyses at this scale have not previously been presented. River flow rate and turbidity data were collected on both rivers for one full year. Turbidity was found to be an excellent surrogate for suspended sediment concentration on both rivers with $\mathrm{r}^{2}$ values greater than 0.87 found. The annual SSFs passing the gauging stations for the River Bandon and River Owenabue were found to be 6012 and 2635 tonnes, respectively. SSF analysis reveals that $85 \%$ and $92 \%$, respectively, of the total annual flux was transported on the Rivers Bandon and Owenabue during the high flow storm-based events. SSFs were investigated at the seasonal, intra- and inter-event scales - the largest 10 SSF events were identified and analysed. Seasonally, most of the flux is delivered in the winter months from October to March. At the intra-event scale, it was found that events of similar flow magnitude do not necessarily transport similar flux levels. Total fluxes were found to decrease for sequential events as a result of sediment exhaustion. At the inter-event scale, hysteresis is observed and analysed for the identified events with clockwise hysteretic loops dominating implying that suspended sediment transport is generally supply limited, and that the primary sources of sediment are located near or within the river.
\end{abstract}

Keywords: Fluxes, hysteresis, loads, storm events, suspended sediment, turbidity.

\section{INTRODUCTION}

The importance of fine sediment transport in river systems has been highlighted in recent studies and the quantification of sediment transport has become a key feature in assessing, for example, water quality trends $[1,2]$ where pollutants may become absorbed into sediments with negative impacts on water quality and thus ecological and recreational uses. Detailed investigation of sediment flux dynamics has been shown to provide river basin managers with valuable information on the mechanisms of euthrophication and has allowed informed decisions regarding water management to be made [3,4].

In an Irish context, work in this area has been limited and detailed analyses of annual flux estimates from continuous datasets are sparse [5]. Furthermore, European studies have identified Ireland as having a paucity of sediment and sediment associated pollutant concentration data [6]. While traditionally Irish waters have been relatively pristine compared with typical European conditions, a decline in water quality has occurred over recent decades [7], a trend, which has continued through to the most recent water quality assessment in 2011 where approximately $30 \%$ of Irish rivers were classified as being polluted [8]. Over the past 10 years, significant work has been undertaken in assessing nutrient losses from Irish catchments to rivers, but this work has not yet included comprehensive analysis of sediment associated nutrient inputs, has concentrated on nutrient loss from land and has been undertaken on small scale catchments $[9,10]$.

Accurate suspended sediment flux (SSF) estimation requires the collection of continuous data but there is considerable cost associated with such labour intensive monitoring programmes. Therefore, 
turbidity has been used as a surrogate for suspended sediment concentration (SSC) because it is less expensive to monitor in the long-term and less labour intensive. Linear relationships between turbidity and SSC have been presented in various studies $[11,12]$.

The objectives of this paper are thus to estimate the true SSF using turbidity as a surrogate for two rivers, to investigate and quantify the influence of storm-based high flow events and their contribution to the annual flux, and to analyse the variation in the flow rate-SSC (Q-SSC) relationship at the intra-event, inter-event and seasonal time-scales.

\section{CATCHMENT CHARACTERISTICS}

The 11,180 km² South Western River Basin District (SWRBD) was established under the EU Water Framework Directive (WFD). The annual average rainfall is $1219 \mathrm{~mm}$ at the Cork Airport gauging station (Fig. 1), which is the nearest long-term rain gauge with hourly data to both catchments with the furthest reach of either catchment being $55 \mathrm{~km}$ from the gauge.

The $74 \mathrm{~km}$ long River Bandon emerges at an elevation of $320 \mathrm{~m}$ ordnance datum (O.D.), drains an area of $608 \mathrm{~km}^{2}$ and has an average slope of $4.6 \mathrm{~m} / \mathrm{km}$. The catchment is dominated by agricultural land, small areas of forestry and small urban areas, and is medium in size in terms of Irish catchments where the largest catchment is less than $5000 \mathrm{~km}^{2}$ in area and the average catchment area is approximately $160 \mathrm{~km}^{2}$. River flow rate response to rainfall events on the River Bandon is slower than that of the Owenabue catchment due to its larger size and shallower river slope.

The $22.7 \mathrm{~km}$ long River Owenabue is a small $105 \mathrm{~km}^{2}$ sub-catchment of the greater Lee catchment. The catchment I located adjacent to the Bandon catchment and the underlying geology is quite similar [13]. The river emerges at an elevation of $170 \mathrm{~m}$ O.D., has an average slope of $6.3 \mathrm{~m} / \mathrm{km}$ and is dominated by agricultural land, forestry and some small urban settlements. The catchment hill slopes are quite steep and response to rainfall is quick with a noticeable increase in river stage within an hour of significant rainfall events. Digitised 15 minute flow rates are available from the Office of Public Works (OPW) at gauged locations on both rivers.

The Curranure gauging station on the River Bandon drains a catchment area of $424 \mathrm{~km}^{2}$, with records available since 1976 over which time the mean flow rate has been $14.9 \mathrm{~m}^{3} / \mathrm{s}$. On the River Owenabue, the Ballea Bridge Gauging station has been in operation since 1956, with a full digitised flow record available from 1974. The station drains a catchment area of $103 \mathrm{~km}^{2}$ and the mean flow rate is $2.3 \mathrm{~m}^{3} / \mathrm{s}$. Stream flows in both rivers are generally greatest between October and March and lower from April to September, which is typical of rivers in Ireland and the United Kingdom.

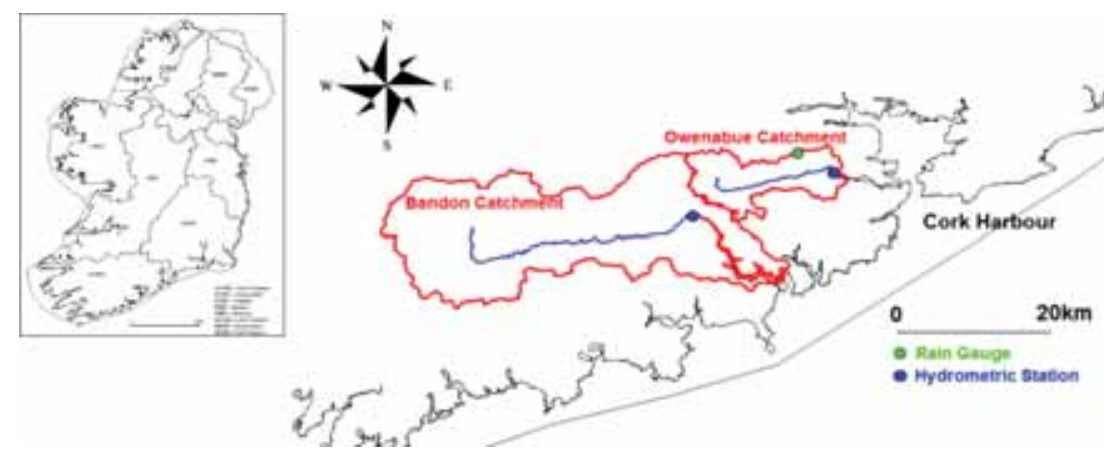

Figure 1: Location of the Rivers Bandon and Owenabue in the SWRBD, Ireland. 


\section{METHODOLOGY}

\subsection{Data gathering}

The Irish OPW operate water level recorders at both gauging stations, which record at 15 minutes intervals. Water level is converted to flow rate using site-specific stage-discharge relationships developed by the OPW. Flow rates at both gauging stations were provided by the OPW in digitised format.

In-situ turbidity was continuously monitored at both the Curranure (Bandon) and Ballea Bridge Lower (Owenabue) hydrometric stations using Campbell Scientific OBS 3+ probes connected to CR800 data-loggers recording at 15-minute intervals. Turbidity was monitored from the 10/02/2010 to $09 / 02 / 2011$ on the River Bandon and from 15/09/2009 to 15/09/2010 on the River Owenabue, during which approximately weekly manual surface grab samples were also collected for the purposes of calibration. The monitoring periods could not be harmonised for both rivers due to data corruption of flow data on the River Owenabue. Additional manually collected suspended sediment samples were collected outside the monitoring period at extreme flows. All samples were collected as far downstream as possible to maximise the catchment contribution but above the limit of tidal intrusion (Fig. 1). One litre sub-samples were collected from the surface grab and subsequently tested in accordance with Method 2540 D of the American Public Health Association (APHA). A vacuum pump was used to reduce filtering times where necessary.

In-situ turbidity measurements were converted to SSC using a linear relationship with SSFs determined by applying eqn (1) where $\mathrm{L}_{s}$ is the load in grams over a time period $\left(t_{2}-t_{1}\right), Q_{t} S S C_{t}$ is the flow rate at time $t$ and $\mathrm{SSC}_{t}$ is the $\mathrm{SSC}$ at time $\mathrm{t}, \mathrm{SSC}_{\mathrm{t}}$ is measured in $\mathrm{mg} / \mathrm{L}$ and $\mathrm{Q}_{\mathrm{t}}$ is measured in $\mathrm{m}^{3} / \mathrm{s}$.

$$
\mathrm{L}_{\mathrm{s}}=\int_{\mathrm{t}_{1}}^{\mathrm{t}_{2}} \mathrm{Q}_{\mathrm{t}} \mathrm{SSC}_{\mathrm{t}} \mathrm{dt}
$$

\subsection{Data analysis}

Storm-based events were identified as occurring when the flow rate equalled or exceeded the $10 \%$ flow exceedance level for each river over the respective monitoring period. Once an event was identified, it was defined as beginning when the SSF rate exceeded the flux rate, which occurred $50 \%$ of the time during the six hydrological winter months (October to March inclusive). These 6 months were selected for two reasons; first to filter smaller events from the record for analysis purposes and second to limit analysis of events with excessive durations, particularly during the winter months. Similar approaches have been adopted by others [14].

\section{RESULTS AND DISCUSSION}

\subsection{Hydrology}

The recorded rainfall for the River Bandon monitoring period was $878 \mathrm{~mm}$, or $72 \%$ of the annual mean. The largest daily rainfall for the monitoring period was $40.7 \mathrm{~mm}$, while the maximum monthly rainfall recorded was $136.7 \mathrm{~mm}$ in January 2011. The average Q for the monitoring period was $11.6 \mathrm{~m}^{3} / \mathrm{s}$, which is $23 \%$ lower than the long-term annual average and reflects the lower than average rainfall over the monitoring period. The discharge frequency percentile Q5:Q95 ratio for the catchment during the monitoring period is 19 . This dimensionless ratio represents the magnitude of the 
infrequent fifth percentile (Q5 - high flow) to the frequent ninety fifth percentile (Q95 - low flow) discharges and is a practical way of assessing the run-off response or flashiness of a catchment [10].

The recorded rainfall for the monitoring period on the Owenabue catchment was $1181 \mathrm{~mm}$, which is $97 \%$ of the long-term annual mean. The largest daily rainfall recorded over the monitoring period was $51.3 \mathrm{~mm}$ and the monthly maximum rainfall for the monitoring period was $246.7 \mathrm{~mm}$ in November 2009. The average $Q$ for the annual monitoring period analysed was $3.08 \mathrm{~m}^{3} / \mathrm{s}$, which is $134 \%$ of the long-term annual average. The large average $\mathrm{Q}$ for the monitoring period can be explained by the intensity of rainfall that fell during the months of November and December where over twice the annual mean rainfall for these months occurred. This resulted in reduced infiltration and increased overland runoff and thus increased flow rates. On the Owenabue, the Q5:Q95 ratio is 26, compared with 19 on the River Bandon. The higher Q5:Q95 ratio for the Owenabue catchment, which may be due to the steeper catchment hill slopes and channel slope since both catchments have similar geomorphology and rainfall regimes.

\subsection{Turbidity - suspended sediment concentration calibration}

Horowitz [1] discussed the timescales over which different sampling programmes can achieve a representative range of site-specific SSC values. The same considerations apply when calibrating turbidity to SSC; it is not desirable to extrapolate significantly beyond the maximum measured values as it may lead to unacceptable errors.

On the River Bandon manual samples were collected over a large and representative discharge range to a maximum flow rate of $209 \mathrm{~m}^{3} / \mathrm{s}$, which is larger than the maximum flow rate measured during the continuous monitoring period. The maximum SSC measured from a manually collected sample on the River Bandon was $114.7 \mathrm{mg} / \mathrm{L}$, which is larger than $99 \%$ of all recorded SSC values estimated from the turbidity record. On the River Owenabue, the maximum Q at which a manual sample was taken was $16.66 \mathrm{~m}^{3} / \mathrm{s}$, which is $85 \%$ of the maximum Q recorded. The maximum SSC measured from a manually collected sample on the River Owenabue was $837 \mathrm{mg} / \mathrm{L}$ or $70 \%$ of the maximum recorded SSC (again using turbidity as a surrogate). However, only five values from the total dataset of 35,000 points (less than $0.02 \%$ ), are higher than the SSC values found from manual sampling. These statistics indicate that the relationships developed are likely to adequately represent the range of SSC values in the rivers.

The turbidity-SSC relationships for both the River Bandon and River Owenabue are presented in Table 1. Variations in grain size distribution (particularly at the coarser sizes) associated with floods, may cause non-linear relationships to occur between turbidity and SSC although Lewis [12] reports that, in practice, linear models work quite well. Measured SSC values are relatively low $(<1000$ $\mathrm{mg} / \mathrm{L}$ ) and based on visual analysis the suspended sediment on the filters generally remains fine $(<63 \mu \mathrm{m})$, even during flood events. In fact, bed sediments collected from both rivers were found to have between $80 \%$ and $90 \%$ of the material passing a $63 \mu \mathrm{m}$ sieve, indicating the fineness of sediments in both rivers [15].

Table 1: Turbidity-SSC relationships for the River Bandon and River Owenabue.

\begin{tabular}{lccc}
\hline River & No. of points $(\mathrm{n})$ & Linear equation & $\begin{array}{c}\text { Co-efficient of } \\
\text { determination }\left(\mathrm{r}^{2}\right)\end{array}$ \\
\hline Bandon & 66 & $\mathrm{SSC}=1.564$ (Turbidity) +2.143 & 0.965 \\
Owenabue & 70 & $\mathrm{SSC}=1.224$ (Turbidity) -0.905 & 0.871 \\
\hline
\end{tabular}




\subsection{Total suspended sediment flux estimates}

The annual SSF for each monitoring period on the River Bandon and River Owenabue is 6012 and 2636 tonnes, respectively. This equates to a suspended sediment yield of $14.2 \mathrm{t} / \mathrm{km}^{2} / \mathrm{yr}$ (tonnes per square kilometre per year) for the Bandon catchment and $25.6 \mathrm{t} / \mathrm{km}^{2} / \mathrm{yr}$ for the Owenabue catchment.

The annual flux analysis reveals that $75 \%$ of the total flux for the River Bandon is transported when the flow rate is above the $10^{\text {th }}$ frequency percentile indicating that transport in the river is significantly influenced by infrequent high flow events when disproportionately large quantities of SSF are transported. On the River Owenabue, $77 \%$ of the total annual flux is transported when the flow rate is above the $10^{\text {th }}$ frequency percentile.

\subsection{The Q-SSC relationship}

Long-term suspended sediment and flow rate records have shown that there is generally a positive correlation between SSC and Q [16,17]. The sediment rating curves for the Rivers Bandon and Owenabue for the monitoring periods are presented in Fig. 2. The co-efficient of determination, $\mathrm{r}^{2}$, for the Rivers Bandon and Owenabue are 0.18 and 0.56 , respectively. The high $\mathrm{r}^{2}$ value found on the River Owenabue indicates that Q is the most important factor in determining the SSC on the river Owenabue. The low value on the River Bandon indicate that SSC values influence more by other factors, such as those described above. When seasonal and stage separation of the data was undertaken, improvements in the $\mathrm{r}^{2}$ values were found, which indicates that the Q-SSC relationship is both seasonal and stage related. Typical explanations for the degree of scatter include: river bank erosion, which can lead to increases in SSC not correlated to Q; differing soil types in sub-catchment, which erode at different scales; topography and land use, which affect the rate of transport of sediments to the river; river flashiness, which can result in large increase/decreases in Q that are independent of SSC; river meander geometry, which influences spatially the concentration of suspended sediment and temporal factors, which influence all of the above factors.

\subsection{Storm-based dynamics of suspended sediment flux}

Analysis of the annual monitoring periods following the criteria presented in Section 3.2 results in 10 storm-based events being identified on each river for their respective monitoring periods (Tables 2 and 3). On the River Bandon there are three events where maximum flow was above the $10^{\text {th }}$ frequency percentile for flow, two events above the $5^{\text {th }}$ percentile and five events above the
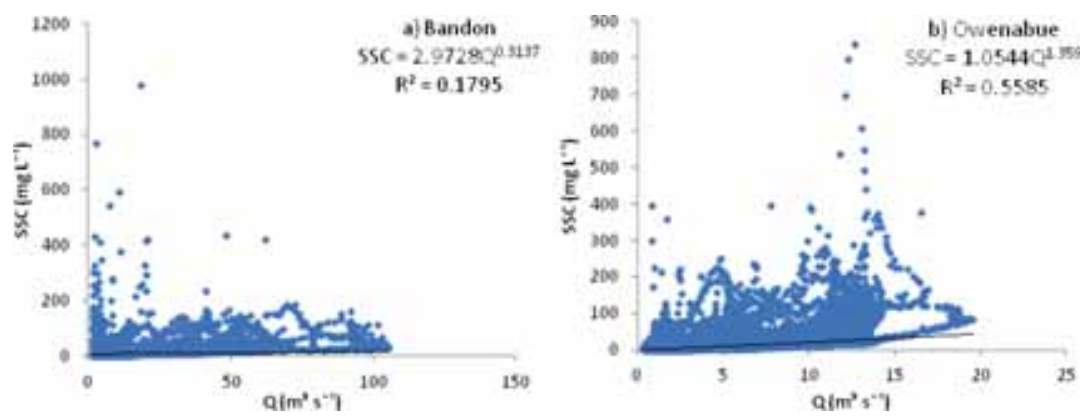

Figure 2: Q-SSC rating curve plots for (a) River Bandon and (b) River Owenabue. 
$2^{\text {nd }}$ percentile. The respective figures on the River Owenabue are four, two and four. On the River Bandon the 10 events identified had a total of 23 peaks in Q, with each event having between 1 and 7 individual peaks. On the River Owenabue the 10 identified events included 28 peaks, 7 of which are associated with Event 2, which occurred in November 2009.

To compare individual events the flux may be normalised to find the average daily flux of each event (Tables 2 and 3). Events 8 and 9 on the River Bandon, both occurring mid-winter, have the

Table 2: Events identified on the River Bandon for the period 10/02/2010 to 09/02/2011.

\begin{tabular}{|c|c|c|c|c|c|c|c|c|c|c|}
\hline 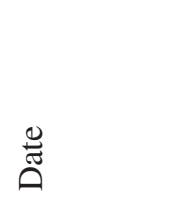 & 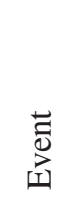 & 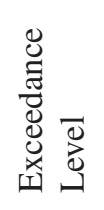 & 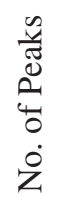 & 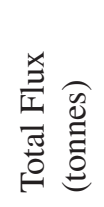 & 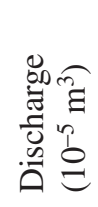 & 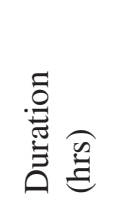 & 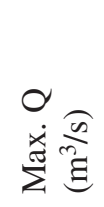 & 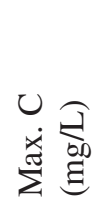 & 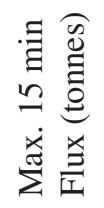 & 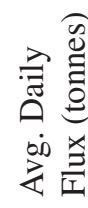 \\
\hline 03/03/2010 & 1 & 10 & 1 & 69 & 23 & 34.75 & 37.9 & 96.3 & 3.3 & 47.8 \\
\hline $18 / 03 / 2010$ & 2 & 10 & 1 & 44 & 36 & 67 & 28.0 & 32.2 & 0.8 & 15.9 \\
\hline 23/03/2010 & 3 & 10 & 1 & 87 & 63 & 90.25 & 34.5 & 54.0 & 1.6 & 23.2 \\
\hline 28/03/2010 & 4 & 2 & 2 & 731 & 344 & 345.75 & 95.7 & 141.2 & 6.8 & 50.8 \\
\hline 09/07/2010 & 5 & 5 & 2 & 223 & 70 & 91.25 & 42.2 & 291.3 & 8.6 & 58.5 \\
\hline $18 / 07 / 2010$ & 6 & 2 & 1 & 337 & 173 & 173.25 & 71.7 & 145.5 & 7.5 & 46.6 \\
\hline $28 / 10 / 2010$ & 7 & 2 & 7 & 1234 & 643 & 694 & 100.6 & 978.7 & 16.3 & 42.7 \\
\hline $26 / 12 / 2010$ & 8 & 2 & 2 & 868 & 279 & 226.75 & 105.6 & 164.8 & 13.1 & 91.9 \\
\hline 07/01/2011 & 9 & 2 & 4 & 1377 & 588 & 402.5 & 185.6 & 125.1 & 18.4 & 82.1 \\
\hline 04/02/2011 & 10 & 5 & 6 & 163 & 150 & 135.5 & 51.4 & 28.6 & 1.2 & 28.9 \\
\hline
\end{tabular}

Table 3: Events identified on the River Owenabue for the period 15/09/2009 to 15/09/2010.

\begin{tabular}{|c|c|c|c|c|c|c|c|c|c|c|}
\hline 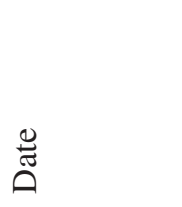 & $\begin{array}{l}\overrightarrow{0} \\
\overrightarrow{0} \\
\text { 咅 }\end{array}$ & 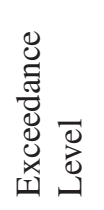 & $\begin{array}{l}n \\
\frac{n}{\tilde{D}} \\
2 \\
4 \\
0 \\
\dot{0} \\
\dot{Z}\end{array}$ & 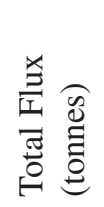 & 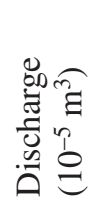 & 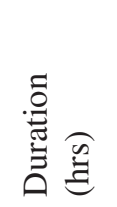 & 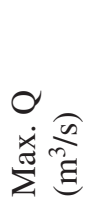 & 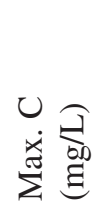 & 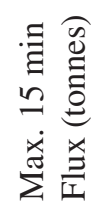 & 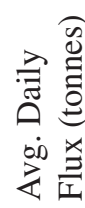 \\
\hline $22 / 10 / 2009$ & 1 & 5 & 3 & 140 & 26 & 137.5 & 11.1 & 389.4 & 3.5 & 24.4 \\
\hline $19 / 11 / 2009$ & 2 & 2 & 7 & 991 & 262 & 761.75 & 19.6 & 836.7 & 9.6 & 31.2 \\
\hline 05/12/2009 & 3 & 10 & 6 & 167 & 71 & 244.75 & 12.7 & 139.3 & 1.4 & 16.4 \\
\hline $31 / 12 / 2009$ & 4 & 2 & 2 & 369 & 58 & 185 & 17.0 & 371.8 & 4.7 & 47.9 \\
\hline $12 / 01 / 2010$ & 5 & 2 & 5 & 442 & 114 & 347.5 & 13.7 & 209.3 & 2.3 & 30.5 \\
\hline $04 / 02 / 2010$ & 6 & 10 & 2 & 55 & 9 & 51 & 10.0 & 251.8 & 2.2 & 25.8 \\
\hline $24 / 03 / 2010$ & 7 & 10 & 1 & 44 & 9 & 69.75 & 7.7 & 162.2 & 1.0 & 15.1 \\
\hline 29/03/2010 & 8 & 2 & 1 & 106 & 15 & 78.5 & 11.6 & 245.3 & 2.5 & 32.4 \\
\hline 06/04/2010 & 9 & 5 & 1 & 56 & 16 & 80 & 11.5 & 117.0 & 1.2 & 16.9 \\
\hline 19/07/2010 & 10 & 10 & 1 & 48 & 7 & 53 & 8.2 & 217.6 & 1.3 & 21.7 \\
\hline
\end{tabular}


highest average daily fluxes and are approximately 30\% larger, in terms of SSF, than the other events. These events are consecutive, with only 2 days between the end of Event 8 and the beginning of Event 9, implying that sediment source exhaustion did not occur at the intra-event scale here. Event 9 is a long duration event with four Q peaks, the largest of which occurs on the 4th Q peak $\left(185.6 \mathrm{~m}^{3} / \mathrm{s}\right)$ and has an approximately 5 -year return period flow rate.

On the River Owenabue, Event 2 contributes the largest quantity of suspended sediment to the total monitoring period at 991 tonnes (although not the largest daily SSF) and influences the annual flux considerably by accounting for $37.6 \%$ of the total annual SSF for the monitoring period. The event has a peak discharge of $19.58 \mathrm{~m}^{3} / \mathrm{s}$, with a return period flow rate of approximately 5 years. On both rivers, the highest SSF occur during the months of November to February. The average daily flux of all events on the River Owenabue is smaller than the corresponding value for the River Bandon. The ratio of average daily flux to mean daily flow rate for the Rivers Bandon and Owenabue are 1.9 and 4, respectively, indicating that the River Owenabue discharges almost twice as much sediment per unit discharge compared with the River Bandon. This is attributed to the smaller catchment size, steeper river gradient and steeper catchment hill slopes as the underlying soils are similar.

\subsection{Intra-event suspended sediment dynamics}

Hysteresis is commonly observed between Q and SSC. Discussion of the possible explanations for varying hysteretic loop shapes has been the subject of a number of papers [17-19]. Williams [17] provides a comprehensive overview of the hysteretic phenomenon and identifies five distinct classes of Q-SSC relationships. The main three relationships are: straight or curved single lines, clockwise loops and anti-clockwise loops. The two remaining loop classes are more complex single line plus a loop and figure of eight loop types. The broadness (openness) of the loop indicates the degree of hysteresis. Steegen et al. [19] described clockwise hysteresis as being due to distant sediment sources. These sources have a longer flow path compared with nearer sources, and the sediment will thus have an increased probability of being deposited upstream of the measuring station, thus leading to reduced SSC on the falling limb of the hydrograph. In contrast, most authors associate clockwise loops with sources of sediment that are located near or within the river system and close to the monitoring location. As an event progresses a successive exhaustion of sediment sources occurs, which leads to lower SSC on the falling limb [3,20]. On both the River Bandon and River Owenabue clockwise hysteresis may be explained by sediment exhaustion rather than settling or deposition because SSC declines prior to any reduction in flow rate. This is supported by the results of the manual sampling programme on both rivers where SSC values were lower on the falling limb compared with the rising limb for equal flow rates.

For each Q peak, hysteretic loops were developed to investigate the causes and dynamics of suspended sediment delivery. On the River Bandon, the types of loop observed are clockwise (65\% of the loops), single line (26\% of the loops) and mixed loops. The individual events generally have a single Q peak, where SSC declines before peak Q or where SSC and Q peak approximately simultaneously. Furthermore, events generally involve a slow increase in SSC compared with a more rapid increase in Q as illustrated during peak 4 of Event 9 in Fig. 3b. Shortly before peak Q, SSC begins to decline rapidly, and after peak Q, the SSC declines more slowly while Q declines rapidly. Peak 1 of Event 8 also has a clockwise loop shape with the exception that two distinct SSC peaks occur caused by two sediment rich waves passing the monitoring station, during which time $\mathrm{Q}$ continues to increase. These are known as secondary sediment peaks and can take place independent of $\mathrm{Q}$ behaviour. For Event 8, Q continues to rise during both SSC peaks and the resulting hysteretic loop 

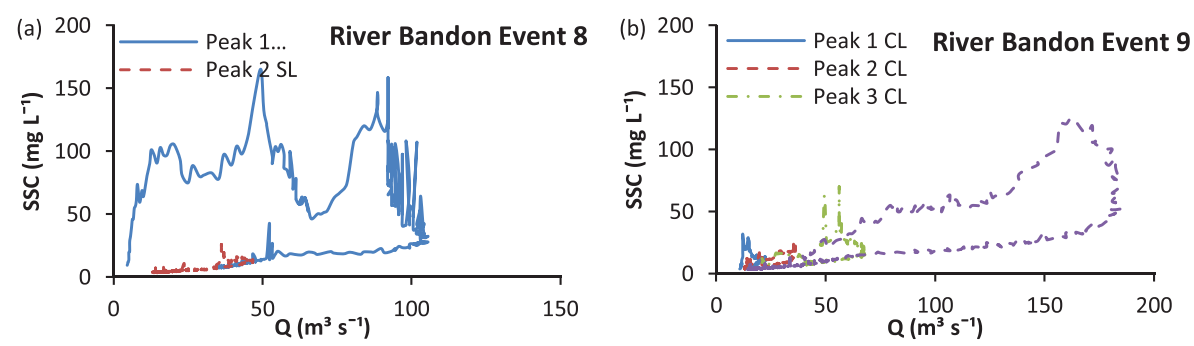

Figure 3: Hysteretic loops for (a) Events 8 and (b) Event 9 on the River Bandon. (Note: CL - clockwise loop, SL - single line).

is clockwise as seen in Fig. 3a. Secondary SSC peaks were found to occur during 7 of the 10 events on the River Bandon and occasionally tertiary SSC peaks were observed. Consecutive SSC peaks like this may be caused by distinct thresholds for sediment re-suspension or sediment supply from different reaches in the catchment. Other possibilities, particularly in larger catchments such as the Bandon, include spatial variations in rainfall and the influence of tributaries, which can have an impact on the SSC dynamics.

Hysteretic loops on the River Owenabue are more complex than the River Bandon for the study periods. On the River Owenabue loop types include clockwise (61\%), single line (14\%), anticlockwise (7\%) and mixed loops (7\%) with the remaining loops both clockwise and anti-clockwise figure-of-eight loops (FEL). Loop shapes are not dominated to the same extent on the River Owenabue by single line or clockwise loops. Mixed loops and anti-clockwise loops always occur during multiple peak events and not during single peak events. The anti-clockwise loops are all associated with secondary sediment peaks where Q is either declining or peaking with the second peak in SSC.

Secondary peaks in SSC were observed during all events on the River Owenabue, indicating that they are common phenomena. A typical secondary SSC peak can be seen in Event 10 on the River Owenabue (Fig. 4). For this event the maximum SSC of the secondary peak is $28 \%$ lower than the initial SSC peak and coincides with peak Q while the initial SSC peak precedes peak Q by 2.5 hours. The initial SSC peak creates a clockwise hysteretic loop, indicating that the primary source may be easily transported re-suspended material from within or close to the river and the monitoring station.

The secondary SSC peak indicates that a late supply of sediment is occurring, which is likely to be from a different source to the initial supply. In this instance the secondary peak arrives at the same time as peak Q, although most of the time secondary SSC peaks lag peak Q. The source is likely to be one that is mobilised early in the storm but has a longer path to travel. The frequency of the secondary SSC peaks on the River Owenabue indicates that it is unlikely to be due to localised bank caving on the falling limb or spatial variation in rainfall within the catchment. Therefore the secondary SSC is most likely explained by the sediment source being located far from the monitoring station, either far upstream or far from the river in the catchment hill slopes. Lenzi and Marchi [11] attributed the initial peak to sediment storage within the river systems remaining from previous events and the secondary peak to sediment from the catchment's sediment source locations. Multiple peaks in SSC can be attributed to different sources and their individual and different travel times to the monitoring station.

Multiple peak events were examined to determine the extent to which sediment depletion occurs at the intra-event scale. For this purpose Event 7 on the River Bandon and Event 2 on the River Owenabue were selected as they have the largest number of peaks per event on each river. Figures 5 


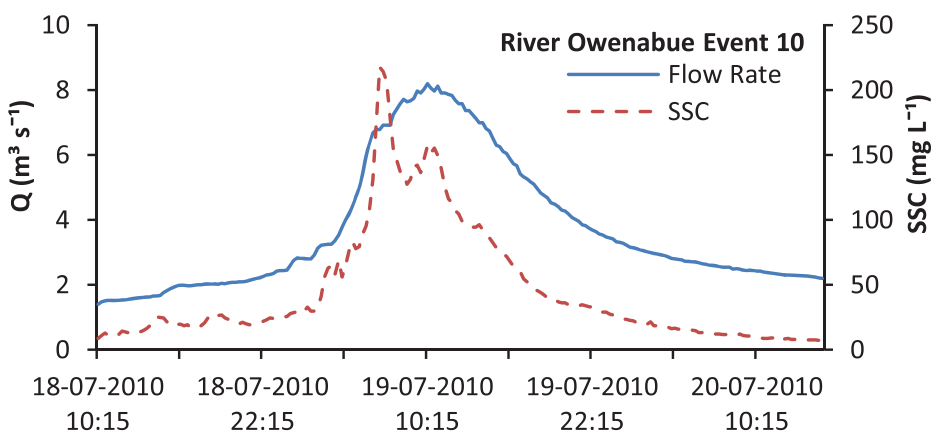

Figure 4: Hydrograph and suspended sediment signal for Event 10 on River Owenabue.

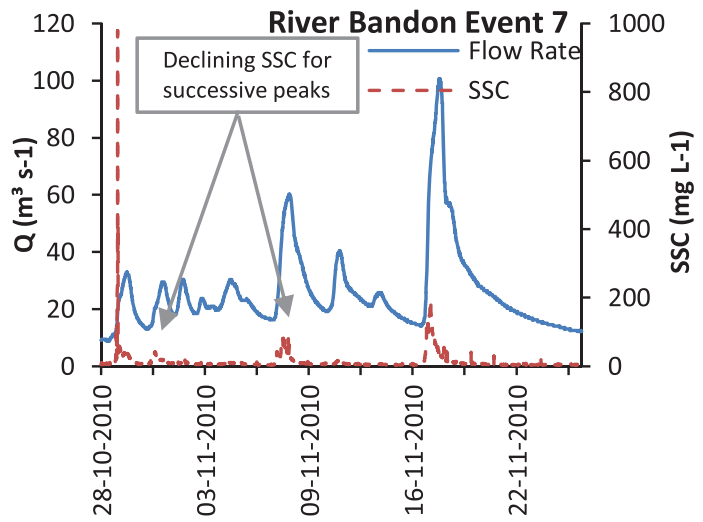

Figure 5: Hydrograph and suspended sediment signal for Event 7 on River Bandon.

and 6 show the hydrographs and suspended sediment signal for each event. These figures show that the SSC reduces progressively with time for successive Q peaks, even where the Q peak is larger than the preceding Q peak. Similar results are found for other events on both rivers, highlighting that sediment exhaustion occurring at the intra-event scale is common to both rivers.

The variation in the Q-SSC relationships, shown in Fig. 2, indicates that the relationship between SSC and Q changes during the events, particularly from the rising to the falling limb. The proportion of the load transported during the rising and falling limbs of each event were assessed. The falling limb was identified as occurring when the $\mathrm{Q}$ value was lower than the $\mathrm{Q}$ value occurring 30 minutes previously. The proportion of the load transported when Q is constant was included in the falling limb load when calculating the annual loads (although this was extremely rare). For the monitoring periods $42 \%$ of the load was transported on the rising limb on the River Bandon while $45 \%$ of the load was transported on the rising limb on the River Owenabue despite rising limb values only occurring $8.7 \%$ of the time on the River Bandon and $22.4 \%$ of the time on the River Owenabue.

On the River Bandon, the SSF is greater on the rising limb for 3 of the 10 events (Events 7, 8 and 9). It is interesting to note that these events are also the largest events in terms of total sediment 


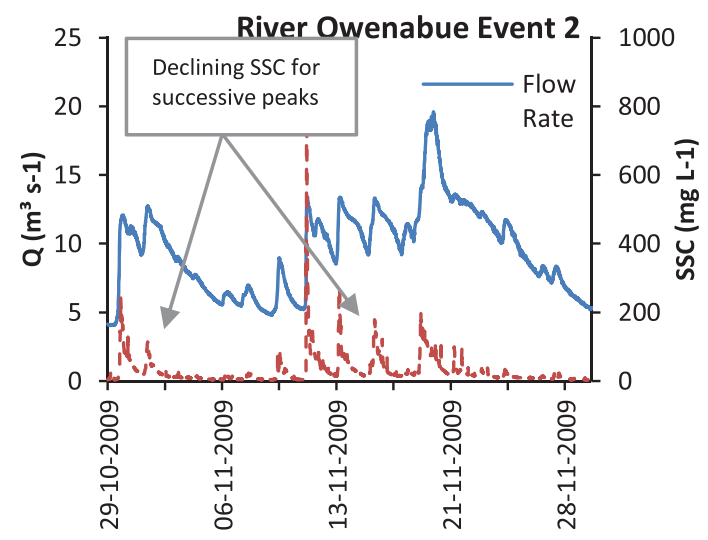

Figure 6: Hydrograph and suspended sediment signal for Event 2 on River Owenabue.

flux, and that these events occur during the months of October to January, during which most of the annual flux is delivered. These results suggest that during the winter months (October to March) when flux rates are high, the rising limb transports most suspended sediment and during the drier summer months (April to September) the falling limb transports the majority of the sediment. The percentage of the load transported on the rising limb for the 10 events on the River Bandon is $40.2 \%$.

On the River Owenabue, 4 of the 10 events transport the majority of the SSF on the rising limb. Three of these events occur during the October to January period, which may indicate that the rising limb delivers the majority of the SSF during the winter period in this region given that on the River Bandon the same pattern is observed. The exception is Event 10; the inclusion of this event may be due to the large (out of season) rainfall during July 2010, which resulted in high SSC values on the rising limb of the hydrograph despite the maximum flow rate only reaching $8.2 \mathrm{~m}^{3} / \mathrm{s}$ (Fig. 6), which is a much lower flow rate than for the other events because it occurs during mid-summer. The suspended sediment signal for Event 10, which has a clockwise hysteric loop, has a steep peak and decline in SSC but also a rapid peak and decline in Q. In total $41.2 \%$ of the total SSF for the 10 events on the River Owenabue is transported on the rising limb.

The primary explanation for such significant quantities of the SSF being transported on the falling limbs of the events is due to the slow decline in both Q, but especially for SSC values after peak Q. Generally, at the beginning of an event, both Q and SSC increase rapidly, but after peaking both Q and SSC decline more slowly and take longer to reach similar levels than before the event, particularly for the $\mathrm{Q}$ value. This phenomenon is more pronounced during the winter months in these catchments when subsurface water flow with low levels of SSC can sustain high flow rates in the rivers after the initial rainfall event.

\subsection{Intra-event changes in the Q-SSC relationship}

Changes in the Q-SSC relationship for different events were examined by developing sediment rating curves for each event for each river. Typical power based curves of the form of eqn (2) were generated where $\alpha$ and $\beta$ are the intercept and exponent constants, respectively, of the power regression.

$$
\mathrm{SSC}=\alpha \mathrm{Q}
$$



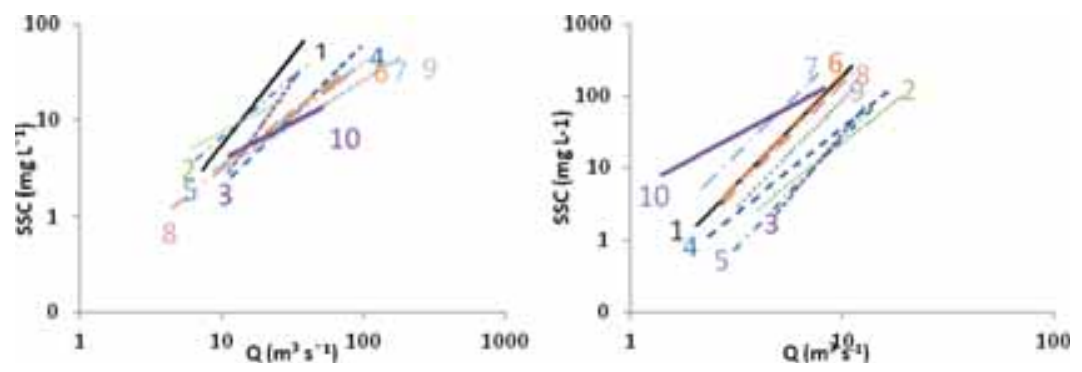

Figure 7: Sediment rating curves for each event for the a) River Bandon and b) River Owenabue.

Asselman [21] attributed $\alpha$ values to an index of erosivity of the material to be transported and $\beta$ values to the erosive power of the river. High $\alpha$ values occur where the suspended sediment source material is easily eroded and high $\beta$ values occur where small increases in $Q$ result in large increases in SSC [22]. Rating parameters cannot be attributed directly to physical meaning, but by comparing the variation of the variables, inferences can be made in relation to the changing Q-SSC relationship.

On the River Bandon, there is a higher degree of variability in the Q-SSC relationship with a $\beta$ value range from 0.764 to 2.114 and an average $\beta$ value of 1.255 (Fig. 7). The $\beta$ values on the River Owenabue range from 2.350 to 3.534 with an average value of 2.894 excluding Event 10 (Fig. 7). Similar results have been reported by Harrington and Harrington [13] at annual, seasonal and stage separated scales.

Rating relationships with similar $\beta$ values indicate a similar rate of change of SSC with respect to Q. The average $\beta$ values (slope of the rating curve) for the River Bandon are approximately 2.5 times lower than for the River Owenabue, indicating that sediment response to changes in flow rate is less intense. This might be expected given that the Bandon is a larger catchment and is less flashy than the Owenabue catchment. The co-efficient of variation (CV) of the $\alpha$ and $\beta$ values showed little variation on the River Bandon (less than 6\%). However, large CV (635\%) were found for the rating parameters of the River Owenabue, which may be attributed to its flashier and smaller catchment.

The shallower rating curves and associated higher $\alpha$ values observed for the River Bandon indicate that a lower proportion of the annual SSF is transported at higher discharges compared to the River Owenabue. This finding is confirmed by the proportion of the suspended sediment load transported by the 10 events on each river. Both rivers discharge between $60 \%$ and $64 \%$ of the annual water discharge during the 10 events identified. However, the Rivers Bandon and Owenabue transports $85 \%$ and $92 \%$, respectively, of the SSF during these events indicating that a large proportion of suspended sediment delivery is associated with higher flows.

The similar $\beta$ values of the rating curves presented in Fig. 7 for the River Owenabue may imply that the power rating curve approach is an appropriate method of estimating SSF on the River Owenabue.

\section{CONCLUSIONS}

The Rivers Bandon and Owenabue drain two different types of catchments in terms of scale and sediment dynamics but the SSF on both rivers is primarily dependent on the river discharge. Turbidity was monitored as a surrogate for SSC on both rivers with results showing that turbidity is an excellent indicator of SSC, where linear regression $\mathrm{r}^{2}$ values accounted for more than $80 \%$ of the 
variability in SSC. The high $\mathrm{r}^{2}$ values for the regressions were primarily due to the fine nature of the suspended sediment, even at high flows.

Annual water discharge and suspended sediment loads for both catchments are dominated by the contribution of high flow storm-based events. This phenomenon is more pronounced for the River Owenabue than for the River Bandon during the monitoring periods, which may be due to a combination of factors including the larger than average flow rates measured during the monitoring period, the steeper river slope and steeper catchment hill slopes of the Owenabue catchment.

Suspended sediment delivery appears to occur in two stages on the River Owenabue. Early increases in SSC may be attributed to the re-suspension of bed material and later secondary increases in SSC may be attributed to source material from the far reaches of the catchment. Separate peaks in SSC are clearly defined on the River Owenabue but less so on the River Bandon.

Event duration was the most significant factor influencing the total SSF of an event. The SSF rate within the events does not significantly influence the total SSF delivery of either catchment. At the intra-event scale, clockwise hysteresis was most common due to sediment exhaustion. This results in a disproportionate quantity of the annual load being transported by the high flow events. The rising limb loads account for a disproportionately large quantity of the SSF on both rivers given its short duration. The extended duration of the falling limb, where there is a slow decline in SSC, results in just over 50\% of the load on each river being transported on the falling limb.

\section{ACKNOWLEDGEMENTS}

The authors wish to acknowledge the research funding received from the Government of Ireland/ Institutes of Technology Technological Sector Research Strand I Postgraduate R\&D Skills Programme and the support received from the Irish OPW in providing river flow and associated data.

\section{REFERENCES}

[1] Horowitz, A.J., Determining annual suspended sediment and sediment-associated trace element and nutrient fluxes. Science of the Total Environment, 400, pp. 315-343, 2008. doi: http://dx.doi.org/10.1016/j.scitotenv.2008.04.022

[2] Zonata, R., Collavini, F., Zaggia, L. \& Zuliani, A., The effect of floods on the transport of suspended sediments and contaminants: a case study from the estuary of the Dese River (Venice Lagoon, Italy). Environmental International, 31, pp. 948-958, 2005. doi: http://dx.doi. org/10.1016/j.envint.2005.05.005

[3] Hudson, P.F., Event sequence and sediment exhaustion in the lower Panuco Basin, Mexico, Catena, 52, pp. 57-76, 2003. doi: http://dx.doi.org/10.1016/s0341-8162(02)00145-5

[4] Gentile, F., Bisantino, T., Corbino, R., Milillo, F., Romano, G. \& Trisorio Liuzzi, G., Monitoring and analysis of suspended sediment transport dynamics in the Carapelle torrent (Southern Italy), Catena, 80, pp. 1-8, 2010. doi: http://dx.doi.org/10.1016/j.catena.2009.08.004

[5] Brebbia, C.A., de Wrachien, D. \& Mambretti S., (eds) Monitoring, Stimulation, Prevention and Remediation of Dense and Debris Flows IV, WIT Transactions on Engineering Sciences, Vol. 73, 2012. doi: http://dx.doi.org/10.2495/deb120011

[6] Vanmaercke, M., Poesen, J., Verstraeten, G., de Vente, J. \& Ocakoglu, F., Sediment yield in Europe: spatial patterns and scale dependency. Geomorphology, 130, pp. 142-161, 2011. doi: http://dx.doi.org/10.1016/j.geomorph.2011.03.010

[7] Earle, R.J., The three rivers project - water quality monitoring and management systems in the Boyne, Liffey and Suir catchments in Ireland. Water Science and Technology, 47(7-8), pp. 217-225, 2003. 
[8] McGarrigle, M., Lucey, J. \& Cinnéide, M., Water Quality in Ireland, ISBN: 978-1-84095-3879, Environmental Protection Agency, Johnstown Castle Estate, County Wexford, Ireland, 2011.

[9] Scanlon, T., Kiely, G. \& Quishi, X., Nested catchment approach for defining the hydrological controls on non-point source transport. Hydrology, 291(3-4), pp. 218-231, 2004. doi: http:// dx.doi.org/10.1016/j.jhydrol.2003.12.036

[10] Jordan, P., Menary, W., Daly, K., Kiely, G., Morgan, G., Byrne, P. \& Moles, R., Patterns and processes of phosphorus transfer from Irish grassland soils to rivers - integration of laboratory and catchment studies. Hydrology, 304, pp. 20-34, 2005. doi: http://dx.doi.org/10.1016/j. jhydrol.2004.07.021

[11] Lenzi, M.A. \& Marchi, L., Suspended sediment load during floods in a small stream of the Dolomites (northeastern Italy). Catena, 39, pp. 267-282, 2000. doi: http://dx.doi.org/10.1016/ s0341-8162(00)00079-5

[12] Lewis, J., Turbidity controlled sampling for suspended sediment load estimation, Erosion and sediment transport measurement in rivers: technology and methodological advances. Proc. Oslo Workshop, 19-20 June 2002, Vol. 283, eds. J. Bogen, F. Tharan \& D. Walling, IAHS Publication:Wallingford, UK, pp. 13-20, 2003.

[13] Harrington, S.T. \& Harrington, J.R., An assessment of the suspended sediment rating curve approach for load estimation. Geomorphology, 185, pp. 27-38, 2013. doi: http://dx.doi. org/10.1016/j.geomorph.2012.12.002

[14] Smith, B.P.G., Naden, P.S., Leeks, G.J.L. \& Wass, P.D., The influence of storm events on fine sediment transport, erosion and deposition within a reach of the River Swale, Yorkshire, U.K., Science of the Total Environment, 314-316, pp. 451-474, 2003. doi: http://dx.doi.org/10.1016/ s0048-9697(03)00068-8

[15] Motherway, K., Sediment budgets in the Irish estuarine environment, Master of Engineering Thesis, Cork Institute of Technology, Ireland, 2008.

[16] Walling, D.E., Suspended sediment and solute yields from a small catchment prior to urbanization, Fluvial Processes in Instrumented Watersheds, eds. K.J Gregory \& D.E Walling, Institute of British Geographers Special Publication. No. 6, pp. 169-192, 1974.

[17] Williams, G.P., Sediment concentration versus water discharge during single hydrologic events in rivers. Journal of Hydrology, 111, pp. 89-106, 1989. doi: http://dx.doi.org/10.1016/00221694(89)90254-0

[18] Klein, M., Anti clockwise hysteresis in suspended sediment concentration during individual storms: Holbeck Catchment, Yorkshire, England. Catena, 11, pp. 251-257, 1984. doi: http:// dx.doi.org/10.1016/0341-8162(84)90014-6

[19] Steegen, A., Govers, G., Nachtergaele, J., Takken, I., Beuselinck, L. \& Poesen, J., Sediment export by water from an agricultural catchment in the Loam Belt of central Belgium. Geomorphology, 33, pp. 25-36, 2000. doi: http://dx.doi.org/10.1016/s0169-555x(99)00108-7

[20] Rodríguez-Blanco, M.L., Taboada-Castro, M.M.,Pallerio,L. \& Taboada-Castro, M.T., Temporal changes in suspended sediment transport in an Atlantic catchment, NW Spain. Geomorphology, 123, pp. 181-188, 2010. doi: http://dx.doi.org/10.1016/j.geomorph.2010.07.015

[21] Asselman, N.E.M., Fitting and interpretation of sediment rating curves. Hydrology, 234, pp. 228-248, 2000. doi: http://dx.doi.org/10.1016/s0022-1694(00)00253-5

[22] Morgan, R.P.C., Soil Erosion and Conservation, 2nd edn., Longman: London, 1995. 